Brief communiaction

\title{
Validation of the Dutch version of the CDC core healthy days measures in a community sample
}

\author{
Jaap Toet ${ }^{1}$, Hein Raat ${ }^{2} \&$ Erik JC van Ameijden ${ }^{1}$ \\ ${ }^{1}$ Department of Epidemiology, Municipal Health Service Utrecht, Utrecht, The Netherlands (E-mail: \\ j.toet@utrecht.nl); ${ }^{2}$ Department of Public Health, Erasmus MC - University Medical Centre Rotterdam, \\ Rotterdam, The Netherlands
}

Accepted in revised form 6 June 2005

\begin{abstract}
An important disadvantage of most indicators of health related quality of life used in public health surveillance is their length. In this study the authors investigated the reliability and validity of a short indicator of health related quality of life, the Dutch version of the four item 'CDC Core Healthy Days Measures' (CDC HRQOL-4). The reliability was evaluated by calculating Cronbach's alpha of the CDC HRQOL-4. The concurrent validity was tested by comparing the CDC HRQOL-4 with three other indicators of health related quality of life, the SF-36, the WHOQoL-BREF and the GHQ-12. The construct validity was evaluated by assessing the ability of the CDC HRQOL-4 to discriminate between respondents with and without a (non-mental) chronic condition, depression, a visit to the general practitioner and use of prescription drugs. Randomly sampled respondents from the city of Utrecht were asked to fill in a questionnaire. 659 respondents (response rate $45 \%$ ) completed the questionnaire. Participants represented the adult, non-institutionalised population of the city of Utrecht, the Netherlands: $58 \%$ women; mean age 41 years; $15 \%$ of non-Dutch origin. The reliability of the CDC HRQOL-4 was good. Cronbach's alpha of three of the four CDC HRQOL-4-items was 0.77 which is good for internal consistent scales. The concurrent validity was good. The four items of the CDC HRQOL-4 showed higher correlations with their corresponding domains of the other instrument than the other domains. Comparison of respondents with or without a chronic condition, depression, visit to the GP and use of prescription drugs produced evidence for an excellent construct validity of the CDC HRQOL-4.
\end{abstract}

Key words: Health related quality of life, Reliability, Validity

\section{Introduction}

Measuring 'health related quality of life' of populations has been an integral part of the work of public health epidemiologists for years [1]. Health related quality of life (HRQoL) or self-reported health status is not only a good predictor of mortality and morbidity [2, 3], but also a good outcome variable when studying trends in the health status of populations $[4,5]$.
The SF-36 [6, 7] is a widely used indicator of HRQoL in nation-wide and local health surveys. Only recently its length is becoming a major problem as other health indicators and risk factors have been included in health surveys. A shorter version of a HRQoL-measure also means far less respondent burden [8]. Several shorter HRQoLmeasures have been developed during the past years, some were abridged versions of the SF-36 (SF-12 [9]; SF-8 [10]; HSQ-12 [11]) others were 
newly developed (EQ-5D [12]; CDC Core Healthy Days Measures, CDC HRQOL-4 [13]). In this study the feasibility, reliability, concurrent and construct validity of the CDC HRQOL-4 was assessed in a general population health survey. The CDC HRQOL-4 was chosen because of its shortness and apparent usefulness in the U.S. Behavioural Risk Factor Surveillance System (BRFSS) [14]

The SF-36 [15, 16], WHO quality of life assessment instrument (WHOQoL-Bref) [17-19] and the General Health Questionnaire (GHQ-12) [20-22] were selected to evaluate the concurrent validity of the CDC HRQOL-4.

The aims of this study were to assess:

(1) the reliability and feasibility of the CDC HRQOL-4

(2) the concurrent and construct validity (extreme groups) of the CDC HRQOL-4

This study was necessary because the CDC HRQOL-4 has not been used before in the Netherlands and cultural differences with the US made it inevitable to assess its reliability, feasibility and validity.

\section{Methods}

\section{Study population and data collection}

Postal questionnaires were sent to a random sample of 1500 people with the Dutch nationality aged 16-75 years, drawn from the municipal

Box 1. 'Healthy Days'-questionnaire

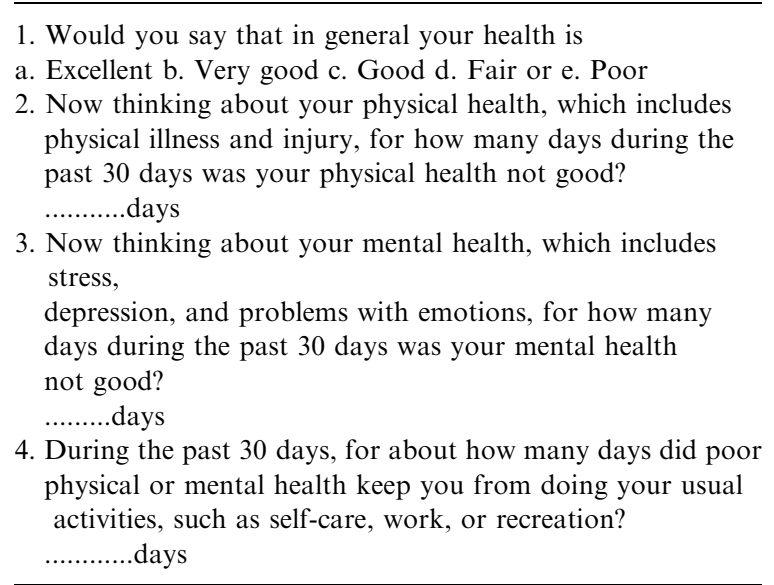

population register of Utrecht (total population of 260,000), the Netherlands. The data collection took place between November 2001 and January 2002. To reduce non-response a reminder was sent to all the subjects 2 weeks after the mailing of the questionnaires.

\section{CDC health related quality of life-4}

The US Centres for Disease Control and Prevention (CDC) developed a set of survey measures to assess a person's sense of well-being through four questions [8] These measures were included in the BRFSS since 1993 [13] and the examination component of the National Health and Nutricion Examination Survey (NHANES) since 2000 (see Box 1). Norwegian [23] and Swedish [24] versions of the CDC HRQOL-4 were developed in the late 1990's.

The Dutch version was translated according to the international guidelines [25] using two independent forward and backward translations.

\section{Analysis}

To evaluate the feasibility of the CDC HRQOL-4 we assessed the percentages of missing answers on the four items, which were compared with those of the three other used measures. Written comments on the questionnaires were analysed to assess whether the respondents encountered any difficulties answering the four items of the CDC HRQOL-4.

Cronbach's alpha was used to evaluate the internal consistency of three of the four CDC HRQOL-4 items.

The concurrent validity was tested by assessing whether the CDC HRQOL-4 items correlated better with their assumed corresponding domains of the SF-36 and WHOQoL BREF than the other domains. Spearman's rank correlation coefficients were used because of the non-normal distribution of the data.

The construct validity (extreme groups) was tested by assessing the ability of the CDC HRQOL-4 to discriminate between respondents with and without a (non-mental) chronic condition, depression, a visit to the general practitioner and use of prescription drugs. 
Mann-Whitney $U$-tests were used to assess the differences between the subgroups.

\section{Results}

\section{Response}

Of the 1500 questionnaires distributed, 659 (45\%) were returned and were eligible for analysis. Another 43 questionnaires were returned to sender because the respondents had moved or were out of the city/country for a longer period (mostly students). More than half of the respondents were female $(58 \%)$ and the mean age was 41 years, $15 \%$ was of non-Dutch ethnic origin. Nearly half of the respondents $(48 \%)$ had completed higher vocational education or university. More than one third of the respondents $(35 \%)$ had a high income (more than 2000 euro's a month). Most respondents were employed $(58 \%)$ and $14 \%$ were student.

\section{Feasibility}

All of the 4 CDC HRQOL-4 items had less than $5 \%$ missing answers, ranging from less than $1 \%$ (self-perceived health) to $4 \%$ (mental unhealthy days and days of activity limitation). In comparison with the other measures used in this study the percentages of missing answers of the CDC HRQOL-4 were reasonable. Analysis of the written comments by the respondents showed no difficulties in answering the four items of the CDC HRQOL-4.

\section{Internal consistency}

Although the CDC HRQOL-4 consist of four items the Cronbach's alpha was calculated for the three items relating to the number of days. The first item ('self-rated health') was omitted because of a different scaling. Cronbach's alpha of the three CDC HRQOL-4 items was 0.77 which is greater than the 0.70 minimal standard recommended for internal consistent scales [26].

\section{Concurrent validity}

The correlations between the CDC HRQOL-4 and the SF-36-domains are shown in Table 1. Selfrated health showed the highest association $(-0,748)$ with the corresponding SF-36 domain. The physically unhealthy days correlated better with the 3 corresponding SF-36 physical-domains than most of the other domains. The mentally unhealthy days had higher correlations with the two SF-36 mental-domains than all the other domains.

The activity limitations days-measure had higher correlations with the two 'role-limitation'domains (physical and mental) and the social functioning-domain than the other domains.

In Table 2 the correlations between the CDC HRQOL-4, the WHOQoL-Bref-domains and the GHQ-12 are shown. Self-rated health and the

Table 1. Concurrent validity of the CDC HRQOL-4 assessed by Spearman correlations between the CDC HRQOL-4 and SF-36domains and -summary scores

\begin{tabular}{|c|c|c|c|c|c|}
\hline \multirow{2}{*}{$\frac{\text { CDC HRQOL-4 } \rightarrow}{\text { SF36-Domains }}$} & \multirow[t]{2}{*}{ Self-rated Health } & \multicolumn{2}{|c|}{ Unhealthy days } & \multirow{2}{*}{$\begin{array}{l}\text { Activity Limitation } \\
\text { days }\end{array}$} & \multirow{2}{*}{$\begin{array}{l}\text { Unhealthy days } \\
\text { (physical \& mental) }\end{array}$} \\
\hline & & Physical & Mental & & \\
\hline Physical Functioning & -0.553 & -0.426 & -0.134 & -0.354 & -0.330 \\
\hline Role Physical & -0.501 & -0.524 & -0.313 & -0.578 & -0.533 \\
\hline Bodily Pain & -0.509 & -0.497 & -0.225 & -0.421 & -0.440 \\
\hline General Health & -0.748 & -0.469 & -0.354 & -0.452 & -0.506 \\
\hline Vitality & -0.490 & -0.366 & -0.585 & -0.492 & -0.608 \\
\hline Social Functioning & -0.464 & -0.473 & -0.588 & -0.651 & -0.691 \\
\hline Role Emotional & -0.311 & -0.249 & -0.655 & -0.518 & -0.561 \\
\hline Mental Health & -0.398 & -0.239 & -0.713 & -0.473 & -0.581 \\
\hline Physical Component Scale & -0.667 & -0.587 & -0.467 & -0.637 & -0.691 \\
\hline Mental Component Scale & -0.587 & -0.449 & -0.687 & -0.628 & -0.736 \\
\hline
\end{tabular}

All correlations are significant at the 0.01 level (2 tailed). 
physically unhealthy days-measure correlated better with the WHOQoL-Bref physical healthdomain than the three other domains. The mentally unhealthy days-measure had a higher correlation with the WHOQoL-Bref mental health-domain than the three other domains.

The GHQ-12 had a higher correlation with the mentally unhealthy days-measure than the three other CDC HRQOL-4-items.

\section{Construct validity}

Table 3 shows the ability of all the five CDC HRQOL-4 to discriminate between respondents without a chronic condition and those with one or more conditions. Respondents suffering from depression also reported higher numbers of unhealthy (both physical and mental) days and days with activity limitation than respondents without a depression. As expected the difference between respondent with or without a depression was the biggest for the mentally unhealthy days (15.5 vs. 2.5 ).

The same ability to discriminate was found for respondents with or without a visit to a general practitioner and the use of prescription drugs.

\section{Discussion}

In this study we examined the feasibility, reliability and validity of the CDC HRQOL-4 in a community survey setting. The feasibility of the CDC HRQOL-4 was good, showing percentages of missing values comparable with the other used instruments and no difficulties in answering the four items.

Table 2. Concurrent validity of the CDC HRQOL-4 assessed by Spearman correlations between the CDC HRQOL-4, WHOQoLBref domains and GHQ-12

\begin{tabular}{|c|c|c|c|c|c|}
\hline \multirow{2}{*}{$\frac{\text { CDC HRQOL-4 } \rightarrow}{\text { WHOQoL-domains }}$} & \multirow{2}{*}{$\begin{array}{l}\text { Self-rated } \\
\text { Health }\end{array}$} & \multicolumn{2}{|c|}{ Unhealthy days } & \multirow{2}{*}{$\begin{array}{l}\text { Activity Limitation } \\
\text { days }\end{array}$} & \multirow{2}{*}{$\begin{array}{l}\text { Unhealthy days } \\
\text { (physical \& mental) }\end{array}$} \\
\hline & & Physical & Mental & & \\
\hline Physical health & -0.609 & -0.481 & -0.463 & -0.543 & -0.610 \\
\hline Mental health & -0.394 & -0.216 & -0.557 & -0.406 & -0.475 \\
\hline Social Relations & -0.371 & -0.220 & -0.323 & -0.263 & -0.342 \\
\hline Environment & -0.447 & -0.313 & -0.322 & -0.377 & -0.373 \\
\hline GHQ-12 & -0.282 & -0.289 & -0.673 & -0.541 & -0.588 \\
\hline
\end{tabular}

All correlations are significant at the 0.01 level (2 tailed).

Table 3. Construct validity of the CDC HRQOL-4 assessed comparing groups with or without a chronic disease, depression, GP-consultations and use of prescription drugs (percentages, means and their Standard Errors)

\begin{tabular}{|c|c|c|c|c|c|}
\hline \multirow{2}{*}{$\frac{\text { CDC HRQOL-4 } \rightarrow}{\text { Groups }}$} & \multirow{2}{*}{$\begin{array}{l}\text { Percentage good } \\
\text { to excellent health }\end{array}$} & \multicolumn{2}{|c|}{ Unhealthy days } & \multirow{2}{*}{$\begin{array}{l}\text { Activity } \\
\text { Limitation days }\end{array}$} & \multirow{2}{*}{$\begin{array}{l}\text { Unhealthy days } \\
\text { (physical \& mental) }\end{array}$} \\
\hline & & Physical & Mental & & \\
\hline \multicolumn{6}{|l|}{ Chronic condition } \\
\hline yes $(n=225)$ & $63 \%$ & $8.5(0.8)$ & $6.4(0.7)$ & $5.9(0.6)$ & $11.5(0.8)$ \\
\hline no $(n=405)$ & $94 \%$ & $2.2(0.3)$ & $3.5(0.3)$ & $2.4(0.3)$ & $5.3(0.4)$ \\
\hline \multicolumn{6}{|l|}{ Depression } \\
\hline yes $(n=101)$ & $59 \%$ & $8.5(1.1)$ & $15.5(1.1)$ & $11.2(1.1)$ & $19.1(1.1)$ \\
\hline no $(n=528)$ & $87 \%$ & $3.6(0.3)$ & $2.5(0.3)$ & $2.2(0.3)$ & $5.3(0.4)$ \\
\hline \multicolumn{6}{|l|}{ Visit to GP (2 months) } \\
\hline yes $(n=266)$ & $72 \%$ & $7.8(0.7)$ & $6.7(0.6)$ & $6.5(0.6)$ & $11.8(0.7)$ \\
\hline no $(n=356)$ & $92 \%$ & $1.9(0.3)$ & $2.8(0.3)$ & $1.6(0.3)$ & $4.1(0.4)$ \\
\hline \multicolumn{6}{|l|}{ Use of prescription drugs } \\
\hline yes $(n=308)$ & $71 \%$ & $6.9(0.6)$ & $5.7(0.5)^{*}$ & $5.6(0.5)$ & $10.3(0.7)$ \\
\hline no $(n=321)$ & $94 \%$ & $2.0(0.3)$ & $3.2(0.3)$ & $1.8(0.3)$ & $4.8(0.4)$ \\
\hline
\end{tabular}

All differences are significant at the 0.001 level $(2$ tailed $)$ except ${ }^{*}(0.01$ level). 
The internal consistency of three of the four CDC HRQOL-4 items was good and comparable with the other instruments used in this study.

The concurrent validity of the CDC HRQOL-4 was good. Comparison with the SF-36 showed higher correlations for CDC HRQOL-4 with their corresponding domain than with the other domains. The same good concurrent validity was found for the comparisons with the WHOQolBREF and the GHQ-12.

Comparison of respondents with or without a chronic condition, depression, visit to the GP and use of prescription drugs produced evidence for an excellent construct validity of the CDC HRQOL-4.

The findings of this study are in accordance with previous validation studies of the CDC HRQOL-4 in the US. Andresen et al. [27] in a spinal cord injured population and Newschaffer [28] in a statewide sample found a good construct validity of the US-version of the CDC HRQOL-4. Diwan and Moriarty [29], Nanda and Andresen [30], Andresen [31] and Moriarty and Zack [32] analysed the CDC-HRQOL-4 in representative samples and found a good internal consistency. They were also able to identify known or suspected population groups with unmet health-related needs. Andresen et al. [33] found a moderate to excellent retest reliability in a study using randomly sampled respondents from the State of Missouri. The only European validation study of the CDC HRQOL-4 by Moum [23] also found a good internal consistency. In the same study the responsiveness of the CDC HRQOL-4 was assessed and the follow-up survey of Norwegian adults showed that response changes were indicative of actual changes in respondent health status.

The main limitation of the study concerns the 'internal' design (only one sample, no retestreliability and no concurrent measurements from external resources). Now that the first results of the validation are promising further studies covering the 'external' aspect can be planned.

The overall conclusion of this study is that the Dutch version of the CDC HRQOL-4 is a promising instrument to replace longer health status measures in public health surveillance in the Netherlands. Further validation studies are needed to assess the psychometric and other methodological aspects of the CDC HRQOL-4 that were not covered by this study and previous validation studies.

\section{Acknowledgements}

This study was supported by Prof Guus van Heck of Tilburg University who supplied the Dutch version of the WHOQoL BREF. We are grateful to David Moriarty of CDC for his support and advice.Conflicts of interest: none

\section{References}

1. Hennessy CH, Moriarty DG, Zack MM, Scherr PA, Brackbill R. Measuring health-related quality of life for public health surveillance. Public Health Reports 1994; 109: 665-672.

2. Idler EL, Benyamani Y. Self-rated health and mortality: A review of 27 community studies. J Health Soc Behav 1997; 38: 21-37.

3. Idler EL, Angel RJ. Self-rated health and mortality in the NHANES-I epidemiologic follow-up study. Am J Public Health 1990; 80: 446-452.

4. Siegel PZ. Self-reported health status: public health surveillance and small-area analysis. In: Schecter S, (ed.), Proceedings of the 1993 NCHS Conference on cognitive aspects of self-reported health status. Hyattsville, Maryland: US Department of Health and Human Services, Public Health Service, National Centre for Health Statistics, 1994

5. Garretsen HFL, van Gilst ECH, van Oers JAM. Collecting health information at a local level. Health Promotion Int 1991; 6: 121-133.

6. Ware JE, Sherbourne C. The MOS 36-item short-form health survey I: Conceptual framework and item selection. Med Care 1992; 30: 473-483.

7. McHorney CA, Ware JE, Raszek AE. The MOS 36-item short-form health survey (SF-36) II: Psychometric and clinical tests of validity in measuring physical and mental health constructs. Med Care 1993; 31: 247-263.

8. CDC. Measuring Healthy Days. Population Assessment of Health-Related Quality of Life. Atlanta: Centres for Disease Control and Prevention, 2000.

9. Jenkinson C, Layte R. Development and testing of the UK SF-12. J Health Serv Res Policy 1997; 2: 14-18.

10. Qmetric. How to Score and Interpret Single-Item Health Status Measures: A Manual for User of the SF-8 TM Health Survey. Qmetric: Lincoln, 2001.

11. Bowling A, Windsor J. Discriminative power of the HSQ12 in relation to age, sex and longstanding illness: Findings from a survey of households in Great Britain. J Epidemiol Commun Health 1997; 51: 564-573.

12. EoroQoL Group. EoroQoL - a new facility for the measurement of health-related quality of life. Health Policy 1990; 16: 199-208. 
13. CDC. Health-related quality of life measures - United States, 1993. MMWR 1995; 44: 95-200.

14. CDC. Quality of life as a new public health measure Behavioural Risk Factor Surveillance System, 1993. MMWR 1994; 43: 375-380.

15. van der Zee K, Sanderman R, Heyink J. De psychometrische kwaliteiten van de MOS 36-item Short Form Health Survey (SF-36) in een Nederlandse populatie. T Soc Gezondheidsz 1993; 71: 183-191.

16. van Dijk A Ph, van Oers JAM, Sturmans F. Test-hertest betrouwbaarheid van de SF-36 in een algemene populatie en in sociaal-economische subgroepen. T Soc Gezondheidsz 2000; 78: 373-381.

17. The WHOQoL Group. The World Health Organisation Quality of Life assessment (WHOQoL): Position paper from the World Health Organisation. Soc Sci Med 1995; 41: 1403-1409.

18. The WHOQoL Group. Development of the World Health Organisation WHOQoL-BREF Quality of Life assessment. Psychol Med 1998; 25: 551-558.

19. Vries J de, Heck GL van. De Nederlandse WHOQoL-100 Tilburg: Tilburg University Press, 1995.

20. Goldberg DP. The detection of psychiatric illness by questionnaire. London: Oxford University Press, 1972.

21. Goldberg DP. A Uses Guide to the General Health Questionnaire. Windsor: Nfer Nelson, 1988.

22. Koeter MJW, Ormel J. General Health Questionnaire. Nederlandse bewerking. Lisse: Swets \& Zeitlinger, 1991.

23. Moum TA. Health-related quality of life in Norway - A nationwide mixed-mode panelstudy of the CDC Healthy Days measures. CDC Quality of life seminar, Atlanta, 1999.

24. Alfredsson J. Har levnadsvanorna förändrats? Resultat från levnadsvaneenkäter 1989, 1994 samt 1999. Gävleborg, Samhällsmedicin, 2000
25. Guillemin F, Bombardier C, Beaton D. Cross-cultural adaptation of health-related quality of life measures: Literature review and proposed guidelines. J Clin Epidemiol 1993; 46: 1417-1432.

26. Bland JM, Altman DG. Cronbach's alfa (Statistics notes). Brit Med J 1997; 314: 572

27. Andresen EM, Fouts BS, Romels JC, Brownson CA. Per formance of health-related quality of life instruments in a spinal cord injured population. Arch Phys Med Rehabil 1999; 80: 877-884.

28. Newshaffer CJ. Validation of Behavioural Risk Factor Surveillance System (BRFSS) HRQoL measures in a statewide sample. Atlanta: CDC, 1998.

29. Diwan S, Moriarty DG. A conceptual framework for identifying unmet health care needs of community dwelling elderly. J Appl Geront 1995; 14: 43-63.

30. Nanda U, Andresen EM. Performance of measures of health-related quality of life and function among disabled adults. Qual Life Res 1998; 7: 644.

31. Andresen EM. Population Measurement of HealthRelated Quality of Life (HRQoL). Qual Life Newslett 1999; 21: 7.

32. Moriarty DG, Zack M. Validation of the CDC's Healthy Days-measures. Qual Life Res 1999; 8: 617.

33. Andresen EM, Catlin TK, Wyrwich KW, JacksonThompson J. Retest reliability of surveillance questions on health related quality of life. J Epdemiol Commun Health 2003; 57: 339-343.

Address for correspondence: J. Toet, MSc, Municipal Health Service Utrecht, Department of Epidemiology, Postbus 2423, 3500 GK Utrecht, The Netherlands

Phone: + 31-30-2863235; Fax: + 31-30-2863344

E-mail: j.toet@utrecht.nl 